\title{
Afoxés em Pernambuco: usos da história na luta por reconhecimento e legitimidade
}

\author{
Ivaldo Marciano de França Lima
}

\section{Introdução}

As práticas e os costumes humanos são construções culturais e isto, até prova em contrário, não é nenhuma novidade entre estudiosos, notadamente os mais afeitos à Antropologia. No tocante a História, ao historicizar os processos de construção das manifestações culturais, pode-se perceber que muitas observações foram feitas (e ainda o são!) de forma naturalizadora, ora tomando o discurso dos "nativos" como plena verdade, ora utilizando-se de narrativas míticas, atribuindo uma origem na perspectiva de entender e traduzir determinado fenômeno. Há também estudos que preconizam por um ponto de vista que atribui às práticas determinadas funçôes ou utilidades, privilegiando às vezes uma das muitas facetas existentes no fazer cultural. Infelizmente ainda hoje existem trabalhos sendo feitos com uma perspectiva que atribui ao "fazer popular" a pecha de sobrevivência, reminiscência ou puro folclore.

Este processo de entendimento das manifestaçôes culturais e religiões de divindades e de entidades no Brasil não é novo, tampouco prática superada entre os estudiosos nos campos da História ou da Antropologia. Por mais que alguns autores da História da Antropologia afirmem a superação do evolucionismo, suas influências persistem em diversos trabalhos sobre as religiões e manifestações culturais negras. ${ }^{1}$ Pode-se conferir ainda hoje trabalhos lançados recentemente que se propõem a buscar as origens das manifestações culturais como forma de entender o maracatu, afoxé, samba ou mesmo o candomblé ou a umbanda. Esta questão, longe de ser de fácil tratamento, reflete parte da complexidade existente nas práticas e costumes ao mesmo tempo em que mostra o quão difícil e árduo é o trabalho daqueles que se propóem a entender homens e mulheres que inventam, fazem e refazem suas práticas no seu dia a dia. E a busca pela origem por parte de alguns estudiosos, sejam eles antropólogos, folcloristas ou historiadores, não deve ser vista dissociada das tramas e enredos vividos por homens e mulheres em busca de legitimidade para suas práticas. Discursos, ideias, versões, mitos e história constituem artifícios para garantir a inserção social ou mesmo o reconhecimento por parte daqueles e daquelas que desejam o predomínio de seus interesses perante os seus pares.

Não se pode em momento algum desvincular da prática e do costume a condição do fazer e do saber humano, o que permite compreender as razões das constantes mudanças presentes em afoxés, maracatus, sambas, e as mais diversas manifestações culturais existentes pelo país afora. São estas manifestações invenções de homens e mulheres, que se apropriam de um sem-número de recursos e de outras invenções das mais variadas cores e "origens", e estas ganham sentidos múltiplos nesse constante fazer e refazer. Os maracatus, manifestação cultural que estudei (e estudo), constituem-se em claro exemplo das mudanças (LIMA, 2005; 2008) encontradas nos diversos grupos existentes em Pernambuco, por mais que alguns autores tenham privilegiado perceber apenas as permanências (REAL, 1990). ${ }^{2}$

Os afoxés pernambucanos também são permeados pelas mudanças, sobretudo quando comparados com seus congêneres baianos. Há, inclusive, diferenças entres os mesmos, como nos mostra Silva (2007), em seu trabalho sobre os afoxés pernambucanos. Mudança é palavra-chave para se entender os modos como os afoxezeiros buscaram legitimidade em uma sociedade permeada por forte sentimento regional (para não usar o termo "bairrismo"), em que o não pernambucano era escorraçado ou simplesmente boicotado. Os afoxezeiros conseguiram razoáveis espaços utilizando-se de vários elementos combinados para afirmarem-se enquanto manifestação cultural autêntica e legítima. 
A mudança em questão, contudo, não poderá ser observada se nosso olhar não estiver relativamente livre de algumas amarras que às vezes as teorias nos impõem. Neste aspecto, sirvo-me das palavras de Barth (2000, p. 108) para afirmar que "devemos tentar olhar para nosso objeto de estudo sem que nossa visão seja excessivamente determinada pelas convenções antropológicas herdadas”, ou, em outras palavras, escutar os nossos informantes com os ouvidos bem abertos e a nossa cabeça disposta a deparar-se com o inusitado e/ou o contrário do que pensamos. Não estou afirmando que devemos "ir ao campo" sem nenhum tipo de conhecimento, posto que isto seria humanamente impossível, mas é imprescindível estabelecer nossas perguntas e questões ao que observamos nas práticas. Pritchard, em célebre trabalho, já discorreu a respeito desta questão (2004).

Mas as transformações não ocorrem apenas nas manifestações culturais. Mesmo nas religiões de divindades e de encantados as adaptações, apropriações e invenções estão presentes, sob todas as formas possíveis, mostrando-nos sua intensa complexidade. Neste sentido, a história e a cultura, em minha visão, é terreno da invenção de seres humanos, e disto não tenho como fugir, caso queira transformar meu desejo de entendimento das práticas e dos costumes em realidade. Afoxés e religiōes não podem ser vistos como frutos da natureza, e, por conseguinte seus liames foram estabelecidos em processos variados ao longo do tempo como forma de resposta para diferentes fins, sendo impossível estabelecer um começo ou origem para tal questão. Como bem afirmou Rocha (1985):

A temática das origens sempre foi uma preocupação de muita gente. (...) Mas a questão da origem (seja do que for) corre o perigo de ser uma falsa questão. Em primeiro lugar, porque quase que todas as origens estariam perdidas, seriam de improvável localização e o que teria ali acontecido são conjecturas, especulações e hipóteses de difícil comprovação. Em segundo lugar, e aqui está o principal, a origem de uma coisa não garante a explicação do seu estado atual. (ROCHA, 1985, p. 11)

No que tange à discussão que por ora desenvolvo, procuro mostrar como o afoxé é implantado em Pernambuco entre o final dos anos 1970 e início dos anos 1980, e de como eles são recebidos pelos intelectuais locais. Minha linha argumentativa segue a perspectiva de que a associação entre afoxés e terreiros de candomblé é construída historicamente, tanto pelos afoxezeiros como pelos praticantes da religião dos orixás.

Esta associação, tomada em vários momentos por diferentes estudiosos, é naturalizada, gerando a estranha impressão de que os afoxés nasceram prontos e acabados, com o atual formato e já ligados aos terreiros, desprezando os movimentos de mudança que aconteceram tanto na Bahia com grupos famosos, a exemplo do Filhos de Gandhy e do Badauê; como em Pernambuco com o Ilê de Egbá. Esta versão naturalizada da História, no entanto, é apropriada e ressignificada pelos afoxezeiros, militantes negros e praticantes das religióes afrodescendentes na perspectiva de buscar legitimidade para os afoxés enquanto manifestação cultural autêntica e reconhecida em Pernambuco. ${ }^{3}$

\section{Os afoxés vistos pelos intelectuais}

Não existem descrições pormenorizadas dos afoxés no século XIX, seja na Bahia ou em qualquer outro local que possam ter existido. Vieira Filho ao discorrer sobre os anos 1880 a 1930 afirma que:

Quanto aos afoxés, pouco sabemos de seus desfiles no período estudado, pois os jornalistas não tinham nenhuma preocupação em descrever as suas passeatas, principalmente por recair sobre esse tipo de manifestação as maiores críticas das elites da época (VIEIRA FILHO, 1998, p. 50).

Além da pequena (ou quase nenhuma) quantidade de vestígios a respeito dos afoxés na Bahia, Raphael Rodrigues torna ainda mais complexa nossa empreitada pela busca de informaçóes e respostas para as questōes colocadas em torno destes grupos, uma vez que “(...) os negros conservavam muitas outras formas de divertimentos carnavalescos. Porém, nesse período, esses folguedos negros são tratados pela literatura sobre o carnaval baiano como se fossem uma única expressão, os afoxés" (VIEIRA FI- 
LHO, 1998, p. 39). Segundo este autor, afoxé era um termo que servia para designar vários grupos, o que de certa forma me permite afirmar a polissemia da palavra, semelhante ao que ocorre com outras no período, a exemplo de batuque, samba e maracatu. ${ }^{4}$

As descriçōes feitas por autores como Maynard (1967, p. 306), Carneiro (1974, p. 123; 1985, p. 47) e Lody (1976) não nos ajudam muito a entender como se organizavam estes grupos em um passado próximo. Suas descrições trazem-nos mais problemas do que respostas uma vez que tomaram as observações de alguns clubes carnavalescos soteropolitanos do final do século XIX e início do XX, feitas por Nina Rodrigues, como sendo desfiles de afoxés. Lody, inclusive, exagera um pouco ao afirmar que: "Nina Rodrigues nos fornece outros informes históricos sobre os afoxés de Salvador: a chegada Africana e os Filhos de África são citados como os grupos mais tradicionais observados pelo estudioso baiano” (LODY, 1976, p. 5).

Outro pequeno exagero deste mesmo autor diz respeito a sua "precisão histórica" ao afirmar que "em 1895, em Salvador, o primeiro grupo de afoxé mostrou publicamente aspectos dos ritos do candomblé" (LODY, 1976, p. 5). Em um exercício de imaginação histórica, por mais que tenha realmente ocorrido um desfile de afoxé no ano referido, como se pode afirmar ter sido este o primeiro diante das inúmeras lacunas existentes na documentação sobre o assunto? Além do mais, o grupo ao qual se refere o autor - muito provavelmente o Embaixada Africana - não era e nem parecia um afoxé, apesar de trazer consigo motivos sobre a África. Mas nada nos autoriza a afirmar que um clube, com enredo, tema e carros alegóricos, pudesse ser chamado por afoxé. Se assim o fosse, "o primeiro afoxé" não seria em nada parecido com os atuais grupos tidos por "tradicionais".

Carneiro também toma as palavras de Nina Rodrigues (2004) como descritivas de grupos de afoxés baianos, atribuindo sentidos que não encontro em seus textos. Há uma relação construída por Carneiro entre o que viu e escreveu Nina Rodrigues com os afoxés, na tentativa de decifrar as origens desta manifestação cultural nos anos mais remotos. Nina Rodrigues, na obra póstuma Os africanos no Brasil (1932), discorre a respeito das danças e do carnaval baiano de seu tempo, mostrando como estes eram percebidos e entendidos pelos seus contemporâneos. Há citações de cartas pedindo a repressão e o fim dos candomblés nas festas carnavalescas, além de comentários do próprio autor sobre dois grupos de grande sucesso no início do século passado, Chegada Africana e Pândegos da África (RODRIGUES, 2004, p. 184-185; p. 208-209). Nina Rodrigues, ao descrever tais grupos, mostra o uso de motivos "africanos" e intui serem os mesmos um "candomblé colossal", mas em nenhum momento usa o termo "afoxé" ou outro sinônimo para esta manifestação. E o que foi por ele descrito em nada lembra os afoxés, segundo a forma como deveriam ser estes grupos, conforme Carneiro e Maynard.

Uma conclusão possível para este uso "indevido" dos textos de Nina Rodrigues por parte de Carneiro é a associação íntima entre afoxé e candomblé, tomada como verdade absoluta pelos intelectuais dos anos posteriores a 1940. Pode-se atribuir a esta relação íntima, construída em via de mão dupla tanto entre os intelectuais como entre os afoxezeiros, a força dos textos de autores como Arthur Ramos, que discorreu sobre os afoxés tratando-os como o "local aonde os pais de santo brincam" (RAMOS, 1934, p. 42). Esta conexão entre a prática cultural e a manifestação, dotada possivelmente de liames estabelecidos pelos próprios afoxezeiros, foi aumentada sobremaneira por intelectuais que não conseguiam enxergar a dinâmica destas construções, atribuindo às mesmas sentidos que elas talvez não possuíssem.

Ao tomar como afoxés os grupos descritos por Nina Rodrigues, Carneiro estabelece uma prova para mostrar a presença destes grupos nos últimos anos do século XIX. E isto é fundamental no tocante à necessidade de ter que explicar as origens de uma manifestação cultural. Uma das mais belas e significativas descrições do carnaval baiano dos estertores do século XIX foi feita por Nina Rodrigues, que informa sobre dois grupos carnavalescos:

Nos Pândegos da África, o carro, descreve um jornal diário, "representa a margem do Rio Zambeze, em cuja riba, reclinado em imensa concha, descansa o rei Labossi, cercado dos seus ministros Auá, Oman, Abato, empunhando o último o estandarte do clube". Após vinha "um carro com dois sócios representando pode- 
rosos influentes da corte do rei - Barborim e Roda. Três cavaleiros precediam a charanga africana que vinha a pé, com os seus instrumentos estridentes e impossíveis". Depois "um carro representando a cabana do pai Ajou e sua mulher com caboré de feitiço, a dar a boa sorte a tudo e a todos". O sucesso deste carro foi enorme. Vimos compacta multidão de negros e mestiços que a ele, pode-se dizer, se haviam incorporado e que o acompanhavam cantando as cantigas africanas, sapateando as suas danças e vitoriando os seus ídolos ou santos que lhes eram mostrados do carro do feitiço. Dir-se-ia um candomblé colossal a perambular pelas ruas da cidade (RODRIGUES, 2004, p. 208).

(...) Ainda o Diário da Bahia: "a chegada Africana, com os clássicos instrumentos e danças, deu no goto de muito papalvo". As danças e cantigas africanas, que se exibiam com este sucesso no carnaval, são as danças e cantos dos candomblés, do culto jeje-iorubano, fortemente radicado em nossa população de cor (RODRIGUES, 2004, p. 209). (negrito nosso)

Não há nenhuma alusão ao afoxé, ou algo que nos permita afirmar que Pândegos da África ou Embaixada Africana fossem grupos congêneres ao Filhos de Gandhy na Bahia, ou Alafin Oyó em Pernambuco. Essa associação entre o que viu e descreveu Nina Rodrigues com os afoxés observados e descritos por Carneiro não se sustenta, sobretudo mediante as discrepâncias entre os dois modelos. A não ser que tenhamos mesmo as palavras "candomblé" e "danças africanas" como sinônimos e evidências para dar aos grupos descritos por Nina Rodrigues o estatuto de afoxés. O que Carneiro tenta, sem ser muito convincente, é erigir uma antiguidade para os afoxés, permitindo-o discorrer sobre suas origens.

Para Carneiro os afoxés quando foram notados pela primeira vez não possuíam esse nome. Para ele "a palavra afoxé, que não se encontra nos dicionários, nada tem de claro. A designação é recente, tão recente que não era conhecida de Nina Rodrigues nem de Manuel Querino” (CARNEIRO, 1974, p. 121). Com esta fórmula, Carneiro consegue um excelente argumento para afirmar que os clubes e agremiaçōes observados por Nina Rodrigues (2004) e Manuel Querino (1988) eram afoxés: “eram certamente afoxés a Embaixada Africana e os Pândegos de África, que fizeram furor nas festas carnavalescas de fins do século passado na Bahia" (CARNEIRO, 1985, p. 47). (Os negritos são meus.) E estes grupos, no entendimento deste autor, são originários da coroação dos reis do congo, irmãos gêmeos dos maracatus-nação recifenses:

(...) não há necessidade de recorrer a tradições originais da África para encontrar o ponto de partida de afoxés e maracatus. Uns e outros são reminiscências dos cortejos dos reis do Congo (CARNEIRO, 1974, p. 124).

Menos conhecido que o maracatu do Recife, também constitui uma reminiscência do cortejo dos reis do Congo o afoxé da Bahia (CARNEIRO, 1985, p. 47).

Em seu ponto de vista, bastante discutível por sinal, defendia Carneiro o fato de que os afoxés existiam desde os tempos das coroaçôes dos reis do congo, e mais uma vez ele constrói uma relação difícil entre maracatus e afoxés como forma de explicar a manifestação cultural "baiana".

Maynard também acompanha esta visão de proximidade entre afoxés e maracatus, corroborando as teses de Carneiro: "O afuxé (sic) baiano tem origem semelhante à do maracatu pernambucano. Ambos da arqueocivilização negra." (Maynard, 1967, p. 304). Raul Lody atribui outra origem para os afoxés, relacionando-os com as festas de Oxum na África e denominadas por domurixá (1976, p. 9).

Vieira Filho também concorda com a tese da origem comum entre afoxés e maracatus, discorrendo da seguinte forma sobre esta questão:

Os autores consultados concordam com o fato dos afoxés terem suas origens comuns aos maracatus de Recife, isto é, os cucumbis e os desfiles dos Reis Congos. Esses fazem parte de uma multiplicidade de manifestaçôes conhecidas como Ciclo dos Reisados, tendo sua ocorrência entre o Natal e o Carnaval (VIEIRA FILHO, 1998, p. 51).

Suas considerações a respeito da relação estabelecida por Carneiro entre os grupos descritos por Nina Rodrigues - Embaixada Africana e Pândegos da África - com os afoxés, no entanto, é de recusa: 
Então podemos dizer que os clubes Embaixada Africana e Pândegos da África, utilizando-se de todo um arsenal simbólico para enaltecer os negros de Salvador, inauguravam uma estratégia conhecida como auto-afirmação (...) Esses clubes uniformizados foram tratados na bibliografia como afoxés, porém acreditamos ser um outro tipo de manifestação já que seus temas de desfile negavam o tribalismo e os candomblés (VIEIRA FILHO: 1998, p. 51). Olga Caciatore considerou tanto o Embaixada Africana como o Pândegos da África como afoxés, mas se levarmos em conta sua própria definição de afoxé não podemos considerar esses dois clubes como representantes dessa expressão cultural (VIEIRA FILHO: 1998, p. 52).

Risério também concorda com a tese de origem única entre afoxés e maracatus, reforçando o esquema em que os primeiros são o "resultado baiano" das coroações dos reis do Congo:

É tese aceita, entre os especialistas, que os afoxés são versões ou reminiscências dos antigos desfiles dos Reis Congos, modo pelo qual, atravessadamente, os escravos negroafricanos, reunidos em confrarias religiosas como a Irmandade do Rosário, podiam participar, lateralmente, das festas católicas do Brasil Colônia (...) (RISÉRIO, 1981, p. 55).

Guerreiro (2000) não deixa explícita sua concordância com a ideia de origem única entre maracatus e afoxés, mas em uma nota de rodapé na página 71 afirma que Carneiro identifica os afoxés com os antigos cortejos dos Reis do Congo surgidos no século XVIII, mostrando, de certa forma, a aceitação da tese de que ambas as manifestações culturais citadas acima são irmãs gêmeas. Guerreiro também defende a relação que foi estabelecida por Carneiro entre as descrições feitas por Nina Rodrigues com os afoxés:

Desde o final do século XIX havia uma outra forma ainda de divertimento negro, que buscava preservar o patrimônio religioso ao mesmo tempo em que constituía um repertório afro-brasileiro. Eram os afoxés, que traziam, durante o carnaval, a temática do candomblé para as ruas da cidade. Segundo Nina Rodrigues, "as danças e cantigas africanas, que se exibiam com este sucesso no carnaval, são as danças e cantos dos candomblés, do culto jeje-iorubano, fortemente radicado na nossa população de cor" (GUERREIRO, 2000, p. 71).

De tal forma, prezado leitor, uma ideia de antiguidade dos afoxés vai se constituindo e sendo fortalecida, a ponto de ainda hoje ser forte o suficiente para ter pouquíssimos questionadores. No entanto, duas conclusões são possíveis de serem tiradas diante desta discussão: ao longo da segunda metade do século XX construiu-se um consenso de que os maracatus e afoxés são "irmãos gêmeos" e que Nina Rodrigues descreveu os mais remotos grupos congêneres aos Filhos de Gandhy da História. Por mais problemática que sejam tais teses, elas ainda são usadas por estudiosos do passado e do presente (como é o caso de Guerreiro) para se referirem aos grupos de afoxés na perspectiva de entendê-los e explicá-los.

\section{Afoxés em Pernambuco: origens e relações com o candomblé}

Para os afoxezeiros pernambucanos, no entanto, os autores acima citados não reuniam poder simbólico suficiente para legitimá-los perante os fortes ataques recebidos de parte considerável dos intelectuais recifenses. Guerra Peixe, no entanto, tomado como principal referência entre os folcloristas e estudiosos pernambucanos para explicar e definir o maracatu-nação (em um longo processo, diga-se de passagem), é tomado como saída e trunfo, para que uma nova versão sobre a origem dos afoxés fosse criada: a de que eles já existiram em um passado remoto em Pernambuco, desaparecendo com o passar dos anos. Essa versão permite certa legitimidade para os afoxezeiros pernambucanos buscarem um lugar ao sol, uma vez que Guerra Peixe afirmou:

(...) No momento, porém, é oportuno revelar que em nossas indagações num maracatu, assinalamos a palavra "afoxé" ou melhor, "afoxé de África", como remoto designativo do folguedo - expressão hoje apenas lembrada por alguns participantes dos mais entendidos. Sabemos que o vocábulo "afoxé" - do sudanês àfohsheh - indica, na Bahia, a espécie de maracatu salvadorense (sic) e nomeava, como explica Arthur Ramos, as festas profanas dos terreiros baianos. A palavra apareceu no Recife, certamente, em virtude da influência religiosa que os sudaneses exerceram sobre os bantos. "Nação" seria, então, o designativo do grupo admi- 
nistrado por governador negro; "afoxé", ou "afoxé de África", a festa profano-religiosa efetuada pela nação no momento oportuno. Os autores que se ocuparam do maracatu recifense não registram "afoxé" nos seus apontamentos, fazendo-nos supor que a expressão se tenha restringido ao âmbito dos seus participantes (...) (PEIXE, 1980, p. 25-26). (negritos e aspas do autor)

Desse modo, por mais que Carneiro, Maynard, Vieira Filho, Risério e Guerreiro tenham afirmado que os afoxés surgiram na Bahia, sendo o irmão soteropolitano dos maracatus recifenses, os afoxezeiros e militantes negros pernambucanos puderam construir outra versão da história, na perspectiva de atribuir outra origem, distinta da baiana, para os congêneres ao Alafin Oyó, Ara Odé e Ilê de Egbá. Guerra Peixe lhes permitiu construir uma versão de defesa dos afoxés baseado na ideia de origem, cara aos folcloristas em geral. Agora os afoxezeiros possuem um poderoso argumento para buscar recursos, subvenções dos poderes públicos e legitimidade na sociedade pernambucana: tratava-se de uma manifestação cultural tão pernambucana quanto os maracatus, mas com uma diferença crucial: estes não possuem a íntima relação com o sagrado. E esta é mais uma história que deve ser esmiuçada.

Não há como afirmar que grupos de afoxés relativamente antigos como Alafin Oyó ou Ara Odé fossem totalmente desprovidos no que tange ao recebimento de recursos por parte do poder público, uma vez que os mesmos constavam na programação das atraçóes para o carnaval de Olinda ao longo dos anos 1990. Constar nesta "grade" era uma garantia de receber uma subvenção, mesmo que isto não representasse grandes somas. Também não se pode negar que outros grupos conseguiam "brechas" para se inserir nos eventos culturais em geral ao longo dos anos 1990. Porém, o novo contexto em que vivem os afoxés é totalmente favorável, uma vez que merecem um dia exclusivo no carnaval recifense (o domingo, no Pátio do Terço), espaços nas programaçôes dos carnavais dos bairros organizados pela Prefeitura da Cidade do Recife, além de presença certa nos eventos carnavalescos das outras cidades do Grande Recife. Os afoxés também possuem um lugar garantido no evento organizado semanalmente pelo Movimento Negro Unificado, no Pátio de São Pedro, denominado por Terça Negra. A única nota negativa para os afoxés no período abordado diz respeito a sua retirada da cerimônia denominada Noite dos Tambores Silenciosos, que acontece todos os anos na segunda-feira de carnaval. A este evento, que ao longo dos anos ganhou forte conotação religiosa, comparecem praticamente todos os grupos de maracatus-nação existentes no Recife e nas cidades vizinhas. Os maracatus-nação reivindicaram um espaço seu, e isto denuncia que no futuro novas disputas poderão surgir, mas desta vez entre maracatuzeiros, que também vivem um momento favorável, e os afoxezeiros. ${ }^{5}$

Não posso afirmar que este momento seja de difícil demarcação, posto que ao longo dos anos 1990 os afoxezeiros e militantes negros interagiram na perspectiva de buscar a legitimidade para que os afoxés fossem aceitos. Contudo, a vitória nas eleições municipais por parte do Partido dos Trabalhadores na capital pernambucana no ano 2000, e a escolha de um ativo militante do movimento negro recifense para dirigir um órgão criado inteiramente para tratar das questões pertinentes à cultura negra (o Núcleo de Cultura Afro) propiciaram uma melhor situação para os afoxés pernambucanos. Tal questão pode ser mais bem percebida no aumento do número de grupos ao longo dos anos 2000, que, segundo o presidente da UAPE (União dos Afoxés de Pernambuco), já passa da casa dos quarenta. Esse contexto, porém, não pode ser creditado única e exclusivamente aos dois mandatos da administração petista na Prefeitura da Cidade do Recife, ou mesmo à ação dos militantes negros no interior desta gestão.

Há que se levar em conta outros elementos, a exemplo do contexto nacional em que os movimentos negros conseguiram o reconhecimento oficial da existência do racismo por parte da presidência da República no ano de 1995 (o grupo de trabalho interministerial) e a aprovação da Lei 10.639 (que obriga as escolas e universidades a incluírem o ensino da história da África e da cultura afrodescendente em seus currículos). Acrescente-se a isso o avanço na aprovação de políticas de ação afirmativa (a exemplo das quotas raciais em várias universidades do país) em vários Estados da federação. A criação da SEPPIR (Secretaria Especial Para a Promoção da Igualdade Racial) foi outra conquista dos movimentos negros 
nos anos 2000 e estes elementos, somados à ação quotidiana dos afoxezeiros ao longo dos anos, permitiriam que se instalasse um contexto favorável aos afoxés pernambucanos. Mas há outro importante elemento presente no discurso dos afoxezeiros na busca pela legitimidade, e que não pode ser desprezado: a ideia de que os afoxés são agremiaçóes religiosas, mais precisamente candomblés de rua.

Em praticamente todas as descrições sobre os afoxés, o sentido de que constituem uma manifestação religiosa é presença garantida. Maynard e Carneiro apontam para essa perspectiva, dando como certas e naturais a associação entre afoxés e candomblés. Para Carneiro, os afoxés:

(...) fazem obrigações religiosas (de propiciação) antes de sair à rua e, em desfile, cantam hinos (cantigas) de exaltação às divindades do candomblé - um repertório cuidadosamente escolhido, composto apenas de hinos fracos, ou seja, que apenas homenageiam os orixás, sem os induzir a descer na cabeça de alguém. (CARNEIRO, 1974, p. 124)

Maynard, ao discorrer sobre o histórico dos afoxés, afirma que estes grupos constituem verdadeiras procissōes religiosas, um candomblé nas ruas baianas:

O afuxé ao sair no carnaval baiano não se mistura com a roda de samba, com as embaixadas, a capueira, o bumba meu boi, com as batucadas alucinantes, porque ele tem características inconfundíveis e dentre elas se destaca a preparação, sem dúvida um ritual religioso (...) o afuxé tem muito de africano: canta em língua nagô, música de ritmo contagiante que enreda o simples espectador de rua a acompanhar com o corpo, quando desfilam pelas vielas, ruas e avenidas da capital baiana (...) Antes de "entrar na dança" há uma preparação ritualística que os afuxés realizam, mostrando-nos o caráter religioso desta dança que torna profana ao partilhar do carnaval. Pode-se mesmo perceber uma mudança sensível nas músicas: quando ainda no terreiro para o "padé de Exu", elas são tristes, logo que passam a desfilar pelas ruas, são alegres, vivas e contagiantes. $\mathrm{O}$ afuxé em conclusão é um candomblé adequado ao carnaval, iniciando com um sacrifício, um despacho para que Exu não interrompa as festividades carnavalescas, é o que pedem nesse "padé de Exu", quando, no centro do terreiro está o que ele mais aprecia: farofa com azeite de dendê (MAYNARD, 1967, 305). (negritos nossos)

A naturalidade com que estes grupos foram tratados, no que diz respeito aos vínculos existentes com os candomblés, permitiu a Lody (1976) descrever o padê de Exu, apontando-o como o início do afoxé:

Como no início dos rituais dos candomblés, quando Exu, o mensageiro é despachado pelo ato do padê, o mesmo ocorre no início das funçōes dos afoxés (...) Essa cerimônia é repetida todas as vezes que as funções iniciam e todos os dias antes do afoxé sair para desfilar no carnaval (...) quem realiza o ato do padê ou mesmo quem ordena tal função é o presidente do grupo de afoxé, que além dos demais encargos é o responsável pelas cerimônias religiosas do afoxé. (p. 9)

Nesse trecho, pode-se perceber como o padê de Exu é visto como algo natural nos afoxés. E o mais complicado é a forma como as relações internas são percebidas, posto que "quem realiza o ato do padê ou mesmo quem ordena tal função é o presidente do grupo de afoxé". Será mesmo que os grupos vivem suas tradiçôes de forma tão estática, sem adaptarem-se às dificuldades momentâneas do cotidiano? Minhas experiências com diversos maracatus-nação no Recife mostram o contrário. Lody vai ainda mais longe nessa perspectiva naturalizadora, afirmando que existem "sobrevivências totêmicas" nos afoxés, o que não pode deixar de ser visto como forte influência da antropologia evolucionista. ${ }^{6} \mathrm{O}$ conceito de sobrevivência totêmica foi uma invenção de Nina Rodrigues, leitor dos textos de Frazer, Tylor e outros teóricos de seu tempo, e foi ao longo do século XX utilizada para definir várias manifestaçôes culturais, a exemplo dos maracatus-nação que traziam consigo símbolos de animais em seus desfiles. (BASTIDE, 1944; 1945; 1959; ALMEIDA, 1942; 1971; ANDRADE, 1982; RAMOS, 1935.) Para estes intelectuais, os animais eram totens, e significavam as reminiscências da época em que os "negros viviam em sociedades totêmicas". No caso dos afoxés, a sobrevivência totêmica em questão é o camelo, presente nos desfiles e apresentações do Filhos de Gandhy. 
A ideia de que os afoxés nasceram atados visceralmente aos terreiros de candomblé não é encontrada apenas nos textos destes três ilustres estudiosos e folcloristas, posto que ainda hoje é defendida por intelectuais contemporâneos, do calibre de Risério e Guerreiro. Ambos reforçam essa ideia, naturalizando a relação construída entre afoxés e candomblés. Para Risério:

Olhando mais de perto a transação mística dos afoxés é bom notar que eles já nasceram ligados a terreiros de candomblé e dirigidos por babalorixás ou outras personalidades do culto. Edison Carneiro cita alguns exemplos, como o do Lordes Ideais, fundado pelo doqueiro José do Gude, ogã do candomblé do Bate-Folha (...) Antes de iniciar o desfile, realiza-se, nos afoxés, uma cerimônia religiosa: o padê, despacho de Exu, entidade mágica que, intermediando entre nós humanos e os orixás, pode fazer com que toda e qualquer festa transcorra em paz e em alegria (....) (RISÉRIO, 1981, p. 56) (negritos nossos)

Para Guerreiro, estudiosa da cultura baiana, os afoxés:

(...) podem ser descritos como "candomblés de rua". Quase todos os membros dos afoxés se vinculam ao culto. Seus músicos são alabês, suas danças reproduzem as dos orixás, seus dirigentes são babalorixás (chefes de terreiro que dominam a língua ioruba) e o ritual do cortejo obedece à disciplina da tradição religiosa. No entanto, a preservação dos fundamentos secretos da religião é observada. A orquestra chamada "charanga”, que executa o ritmo ijexá, é composta de agogôs, xequerês e três tipos de atabaques (rum, rumpi e lê), tal como nas cerimônias religiosas (GUERREIRO, 2000, p. 71-72).

Nessa perspectiva, os afoxés não podem ser vistos como construções culturais, posto que aparece como naturalizado. Sobre esta questão, de que todas as práticas humanas são construídas, Barth sugere também a percepção de que as realidades em que se inserem também o são, ou seja: "Essas pessoas, contudo, bem como qualquer um de nós, necessariamente agem de acordo com sua percepção de mundo, impregnando-o com o resultado de suas próprias construçóes" (BARTH, 2000, p. 111). Reforçando o que o próprio Barth afirma, devo insistir que no fazer do afoxé está presente a mudança/o fazer, que pode ser mais bem entendido nas palavras do já citado autor que diz que "a realidade de todas as pessoas é composta de construções culturais, sustentadas de modo eficaz tanto pelo mútuo consentimento quanto por causas materiais inevitáveis" (BARTH, 2000, p. 111). Mas as mudanças ocorrem de fato nos afoxés? Pode-se percebê-las nos grupos baianos e pernambucanos?

As mudanças nos afoxés foram percebidas pelos autores da bibliografia compulsada como descaracterizaçôes ou perda dos sentidos originais. Por mais que não seja possível descrever um "afoxé original" ou mesmo estabelecer o modelo a partir da descrição feita por Nina Rodrigues, autores como Maynard, Carneiro, Lody, Risério e Guerreiro foram enfáticos ao ressaltarem que estas mudanças não coadunavam com o que "estava nos planos do que pedia a tradição." Os grupos surgidos nos anos 1970 e 1980 na Bahia foram apontados como descaracterizados ou "não muito sérios". Este último argumento, por sinal, é bastante recorrente entre os afoxezeiros pernambucanos, que afirmam ter uma relação com o sagrado de forma mais rígida, ao contrário dos atuais grupos baianos. Risério, ao discorrer sobre o Filhos de Gandhy, afirma que o mesmo é o último a manter esta relação com o sagrado baseada na ortodoxia. Em sua narrativa, trata este grupo com destaque e respeito, mostrando-o como uma exceção, em meio aos novos grupos que surgiam nos anos 1970 na Bahia. Estes últimos, a seu ver, possuíam certa dose de religiosidade:

(...) Agora é preciso esclarecer que quase tudo o que foi dito até aqui pertence já, e em muito boa medida, ao passado. Neste sentido, o afoxé Filhos de Gandhi é uma exceção. Gil que o diga: "o afoxé Filhos de Gandhi é uma transação de iniciados. A maioria deles é feita de homens do culto de candomblé. Quem não tem negócio, não vai lá não". O mesmo não pode ser dito dos novos afoxés e blocos afro. Para usar uma expressão de Eduardo de Ijexá, atualmente já não há tanta "rigorosidade” (RISÉRIO, 1981, p. 57).

Não há "tanta religiosidade" nos mais novos grupos que surgem e estes são a nota destoante do cenário marcado pelo Filhos de Gandhy. O Afoxé Badauê, para Risério, é diferente do que até então se tinha como modelo. Suas palavras, mesmo não sendo deselegantes, mostram um pouco do tom que os novos grupos ganharam de parte significativa dos intelectuais baianos no período: 
Veja-se o caso do afoxé Badauê. Moa é sincero, diz logo que o pessoal de lá não entende muito de candomblé ("a gente só sabe um pouquinho"). "Nós somos esforçados, somos curiosos", diz ele. E acrescenta: "quem entende mesmo, não quer ensinar". O Badauê não tem nenhum vínculo especial com qualquer terreiro de candomblé (RISÉRIO, 1981, p. 57).

Guerreiro, contudo, é mais enfática ao mostrar que os novos grupos não estão cumprindo a regra, permitindo modificações e adaptações em seu interior:

Outros afoxés, formados entre os anos 70 e 80, como Oju Obá, Olori e o mais famoso deles, o Badauê, já não obedeciam à tradição religiosa e a participação das pessoas ligadas aos terreiros não era rigorosamente observada. Segundo Gilberto Gil, o Badauê, reverenciado por Caetano Veloso na canção "sim/não", "é uma espécie de afoxé jovem, uma afoxé pop, progressivo". Estes novos afoxés foram acusados de terem profanado os elementos sagrados, entre eles a batida ijexá, pois os cânticos já não eram obrigatoriamente recolhidos do repertório litúrgico dos cultos e as danças dos orixás eram apresentadas livremente (GUERREIRO, 2000, p. 72).

Já o Afoxé Filhos de Gandhy, este sim, "autêntico e tradicional”, recebe a seguinte descrição de Guerreiro:

De todos os antigos afoxés que a Bahia conheceu ao longo do século, somente o Gandhy se mantém vivo e fiel a todos os elementos rituais, reafirmando continuamente a relação visceral entre o carnaval negro de Salvador e o candomblé, além de servir de inspiração para os vários novos afoxés (GUERREIRO, 2000, p. 77).

Aqui é preciso insistir mais uma vez nos conselhos de Barth: "A teoria e os conceitos antropológicos devem ser testados na análise da vida, tal como ela ocorre em um determinado lugar do mundo" (BARTH, 2000, p. 108). Ora, a autora não consegue perceber que o Filhos de Gandhy é mudança, criação e transformação. A poderosa afirmação que o coloca na condição de o "único", termo usado também por Risério, oculta as adaptações que este grupo estabeleceu ao longo dos anos, a exemplo da substituição do ídolo de madeira denominado "babalotim" pelo retrato de Mahatma Gandhi. Um afoxé "tradicional", segundo as descriçôes de Carneiro, deveria ter um destes ídolos de madeira, pois se trata de parte significativa do elemento religioso entre os grupos do "passado". Tradição, nesta perspectiva, não se renova e nem se atualiza. Repete-se simplesmente, como se as pessoas não soubessem o que fazem, conforme nos ensinou Cascudo (2000) no prefácio de Vaqueiros e cantadores. Tenho certeza, contudo, que toda e qualquer prática é possuidora de sentidos e significados, por mais que alguns folcloristas ainda hoje não consigam perceber isso. Em Pernambuco, o babalotim é praticamente usado por todos os afoxés existentes. Isto reforça minha desconfiança de que o forte discurso da diferença dos afoxezeiros pernambucanos em relação aos grupos baianos é mais um elemento da estratégia de busca pela legitimidade a partir do argumento de rigor na relação com o sagrado. Outras mudanças estão presentes no Afoxé Filhos de Gandhy, mas Guerreiro não consegue percebê-las, preferindo dar a este grupo o status de "último" e "único" que ainda mantém a "tradição" dos antigos afoxés baianos.

Ora, em plena efervescência política, fruto do surgimento de blocos com perspectivas políticas, e um processo de recrudescimento da luta contra o racismo e a discriminação racial, consubstanciadas na fundação de várias entidades negras, a exemplo do Movimento Negro Unificado em 1979, era de se esperar que os novos grupos flexibilizassem suas regras internas e se adaptassem ao novo contexto. Novas entidades afro surgem na Bahia e os afoxés acompanham essa história. As mudanças demonstram que os afoxés são feitos por homens e mulheres, passíveis de adaptações e o Badauê, junto com os demais afoxés baianos que surgem "desligados do sagrado", constitui a maior prova de que a relação entre estes grupos e o candomblé é fruto de uma construção feita por homens e mulheres.

E os afoxés em Pernambuco também estão sendo construídos nesse período de mudanças, de lutas e batalhas na denúncia da "democracia racial brasileira". Neste ínterim, o afoxé Alafin Oyó também é vítima de um discurso que engessa a prática, pois o grosso de seus integrantes ao longo dos anos 1990 era oriundo de várias camadas sociais e não frequentavam um único terreiro, aliás, havia mesmo aque- 
les que nem sequer colocavam os pés em um destes templos de orixás. Pode-se, então, dizer que não era ou nunca foi um afoxé legítimo devido à ausência de elementos religiosos ortodoxos, como os grupos baianos descritos por Carneiro, Maynard, Lody, Risério e Guerreiro? Mas estes grupos que surgem em Pernambuco seguem à risca o modelo de tradição dos afoxés baianos?

\section{Afoxés em Pernambuco: um campo em disputa}

Os primeiros afoxés em Pernambuco surgem ao longo dos anos 1980. Há relatos entre os afoxezeiros de que o primeiro grupo surgido nestas terras foi o Ilê de África, ao passo que outros tomam o Ara Odé, Odolu Pandá e o Axé Nagô como pioneiros. Ressalte-se que este último grupo foi articulado por militantes do MNU como instrumento de luta e organização no processo de militância política. Um dado curioso se apresenta no cenário pernambucano: os afoxés estão imersos em estratégias de luta política, e pode-se dizer que são o resultado disso. O componente religioso, no entanto, vai se constituindo neste processo em que as identidades se redefinem no tocante ao que é ser negro, como afirma a letra de um dos mais populares afoxés locais: "Aprendi com Matamba a jogar capoeira e viver candomblé, ser original, tocar berimbau e dançar afoxé." Ser negro, neste aspecto, é viver a cultura ancestral, "herdada da África" e "trazida" pelos homens e mulheres que aqui chegaram sob a condição de escravos.

A África, o lugar que ocupa no imaginário e na construção de identidades, tem sido largamente discutida por diversos intelectuais. Essa questão, também central nessa discussão, foi sintetizada por Stuart Hall ao afirmar que a África é como útero de mãe para onde sempre se quer voltar. Não se pode pensar a cultura negra na contemporaneidade sem se pensar o lugar ocupado por essa África mitificada. É inútil querer mascarar a perda resultante da diáspora africana, pois "o passado continua a nos falar. Mas já não é como um simples passado factual que se dirige a nós, pois nossa relação com ele, como a relação de uma criança com a mãe, é sempre já 'depois da separação'. É construído por intermédio de memória, fantasia, narrativa e mito" (HALL, 1996, p. 70). É por isso que a volta à terra natal está quase sempre no horizonte, como desejo pulsante, de ser de novo um só com a mãe. "Quem não conheceu, (...), uma opressiva nostalgia por origens perdidas, pelos 'tempos passados'? Entretanto, esse retorno (...) não pode ser realizado nem esquecido e é, pois, o começo do simbólico, da representação, a fonte infinitamente renovável de desejo, memória, mito, busca, descoberta - em suma, o reservatório de nossas narrativas..." (HALL, 1996, p. 75). ${ }^{7}$

Estes afoxés que surgem em Pernambuco, os primeiros e mais antigos dentre os muitos que atualmente existem, diferiam em muito no que tange a sua composição. Refiro-me ao fato de que os principais articuladores destes grupos, excetuando o caso do Ara Odé, eram negros e negras das camadas médias urbanas das cidades de Olinda e Recife e, em sua maioria, militantes da questão racial. Por conhecer bem o Alafin Oyó nestes anos 1990, posso afirmar que seus integrantes não residiam em uma mesma comunidade, e tampouco eram fiéis de um mesmo terreiro, sendo que alguns eram radicalmente ateus.

O Alafin Oyó surge mesmo como um espaço aglutinador de uma identidade negra em construção, como um polo que possibilitava a negros e negras das classes médias se reunirem e articularem novos mundos em que não seriam vítimas do preconceito e da discriminação racial. Por isso a ele acorriam homens e mulheres das cidades de Paulista (onde residiu por muitos anos duas de suas mais destacadas presidentes), Olinda, Recife, Camaragibe e outras tantas. Em diversos jornais de entidades negras nos anos 1990 o Alafin Oyó é retratado com destaque, disputando espaços nas preferências dos militantes negros com os maracatus e demais grupos de afoxés. Por sinal, pode-se dizer que, se no final dos anos 1990 o Ilê de Egbá conquistou espaços e conseguiu realizar shows pelo país e no exterior, o Alafin ainda manteve a aura de ser o ponto de encontro da comunidade negra pernambucana. A referência construída ao longo dos anos que se seguiram ao seu surgimento nos anos 1980 foi marcada pela estreita associação com outras entidades do movimento negro. ${ }^{8}$

Em Pernambuco a íntima relação dos afoxés com o candomblé é tomada como uma maneira por excelência para conferir legitimidade e inserção entre as manifestações culturais aceitas. Mais um indí- 
cio de que os liames entre candomblés e afoxés são construídos. Se os afoxezeiros atuais afirmam que sequer o Filhos de Gandhy mantém o rigor da relação com o sagrado, há que se levar em conta o fato de que a relação com os terreiros é crucial no sentido de conferir alteridade por parte dos grupos pernambucanos perante os baianos. Mesmo entre os maracatuzeiros, a relação com o sagrado é necessária para conferir legitimidade, por mais que alguns grupos reconhecidos como "naçóes" sequer tenham relações íntimas com um terreiro.

Em suma, os afoxezeiros buscaram (e buscam!) ressaltar a diferença com os grupos baianos. A tese de que estes não possuem mais os vínculos com o sagrado é fundamental para marcar a alteridade, mas há ainda o mito da origem baiana, e, por conseguinte, os grupos pernambucanos não seriam legítimos, dignos de reconhecimento entre os pernambucanos.

Diante deste campo em disputa não é raro encontrarmos afoxezeiros que recorrem à bibliografia comentada acima como recurso para angariar legitimidade para seus argumentos e práticas. Nesse sentido, a história dos grupos de afoxés ultrapassou há muito os muros da academia e se tornou um importante argumento nas disputas políticas e culturais em questão. Trata-se, evidentemente, de uma cultura histórica que se formou entre os praticantes dessas manifestações culturais, que tem claros objetivos políticos e identitários. Os militantes negros reinterpretaram a história e os autores, principalmente os folcloristas, utilizando-se da tese de que os afoxés também são pernambucanos e existiram em um passado distante. Os usos da história entre os afoxés aparecem claramente com sentidos políticos, na medida em que fornecem argumentos para legitimar uma manifestação cultural que foi e tem sido recorrentemente combatida como "baiana". Os afoxés pernambucanos também tiveram que se legitimar diante dos maracatus, tidos como autênticas manifestações culturais negras pernambucanas, e nesse sentido a "história" conferiu razão de ser para sua existência na atualidade.

Os usos da história permitiram que os afoxés angariassem legitimidade em Pernambuco, mas também diante dos grupos baianos, que passaram a ser vistos como não muito sérios perante a suposta ortodoxia mantida pelos grupos pernambucanos. Assim sendo, o afoxé sempre existiu em Pernambuco e ao mesmo tempo é uma herança africana, podendo ser praticada sem nenhum constrangimento nestas terras. Esta ideia pode ser atestada no texto de Lindivaldo Júnior, renomado militante negro em Pernambuco:

(...) Se a escravidão isolou e segregou os indivíduos, também determinou um esforço coletivo de reação quanto ao regime de vida que lhes foi imposto. Para além da resistência política, a mãe África nos presenteou com a sabedoria milenar dos búzios, o oráculo divino que orienta a religião afro e traz a fala das divindades africanas para o nosso cotidiano. Trouxe o conhecimento da vida comunitária traduzida em quilombos espalhados por todo o território nacional, e nos deu presentes preciosos como as ricas manifestações culturais, tão singulares, a exemplo do nosso afoxé. No Recife, essa rica expressão do povo negro é irmã do maracatu, essa meditação de rua chamada afoxé nasce por dentro dos primeiros cortejos de maracatu de baque-virado (manifestação surgida a partir da instituição dos reis de Congo, utilizada para dominar os negros, mas transformada em expressão de liberdade pela comunidade). A palavra de origem sudanesa áfohsheih aparece em virtude da influência do povo sudanês sobre os bantus, utilizada para designar nação e grupos administrados por governador negro. Seria, então, afoxé de África a festa profano-religiosa. Talvez venha daí a relação com o maracatu. O afoxé é hoje expressão artístico-religiosa e também carnavalesca da população negra com maior definição estética de nação africana. A concepção que faz a beleza do afoxé é tão africana quanto as nações do candomblé brasileiro. (negritos nossos) ${ }^{9}$

O afoxé é ao mesmo tempo, criação do povo negro pernambucano, irmão gêmeo do maracatu e herança africana, completando a tríade que justifica, de forma magistral, a existência destes grupos na "terra do frevo". Se os folcloristas indagam a respeito da ausência dos afoxés nos anos 1970, os afoxezeiros afirmam que os grupos aqui existentes desapareceram no início do século XX, em clara alusão ao texto de Guerra Peixe ao qual já me referi. O afoxé é legitimamente pernambucano por ser negro ou porque existiu aqui no passado. Eis alguns dos elementos presentes nas falas dos afoxezeiros locais. $\mathrm{O}$ sagrado em questão, forte marca de grupos como Alafin Oyó e Ilê de Egbá, não pode ser visto como natural por 
parte dos intelectuais e estudiosos. Trata-se de uma construção, e nesse caso, que confere legitimidade, ao mesmo tempo em que se insere no processo de construção identitária. Mas é preciso distinguir as diferenças dos grupos atuais, que passam da casa dos quarenta, para aqueles criados ainda nos anos 1980. Devo confessar que necessito ainda continuar "no campo" ouvindo os afoxezeiros, perguntando sobre as formas e os modos como se organizavam seus grupos em um passado recente, cerca de vinte anos atrás. Ao que me parece, os vetores principais de grupos como Alafin Oyó nos anos 1980 e início dos anos 1990 eram o prazer, o lazer e a identidade negra, ao passo que nos dias atuais há certo compartilhamento de práticas em grupos pequenos, em sua maioria ligados a um terreiro em que se pratica a religião dos orixás. Este compartilhamento de práticas e hábitos refere-se ao fato dos integrantes destes novos afoxés residirem nas mesmas comunidades, o que estabelece um paralelo com os maracatus-nação atuais.

Quando afirmei no início deste trabalho que os liames entre os terreiros e os afoxés são fruto de uma construção histórica, com certeza apoiei-me na ideia de que toda e qualquer prática humana é construída, e como tal afeita a mudanças. Discorri sobre os grupos baianos como forma de mostrar os modos como foram discutidos pelos folcloristas e intelectuais contemporâneos na perspectiva de indicar algumas das razóes e justificativas presentes na prática e na fala dos afoxezeiros pernambucanos, ao mesmo tempo em que procurei apontar para o uso da história como forma de obter legitimidade. Os afoxezeiros pernambucanos construíram seus afoxés e continuam seguindo o curso da história, modificando sua prática ao sabor do quotidiano, disputando espaços com os maracatuzeiros e se inserindo no cenário político atual. Eis algumas das questões que necessitam ainda serem mais bem trabalhadas, mas isso é motivo para outras histórias.

\section{Notas}

${ }^{1}$ Estou utilizando o termo "negro", como complemento para o termo "cultura", por recusar outros conceitos largamente utilizados, a exemplo de afro-brasileiro, afrodescendente ou matriz africana. Minha recusa se dá em função de considerar tais termos inapropriados para o devido entendimento das práticas e costumes construídas por negros e negras em nosso país. Para as religiōes, utilizo-me de outro conceito, ou seja, quando os orixás ou voduns são a principal referência, utilizo o termo "religiōes de divindades"; e para as que são formadas por entidades, uso o conceito de "religiōes de encantados" ou de "entidades". Sobre esta discussão, ver a introdução de LIMA (2009).

${ }^{2}$ Ao referir-se aos maracatus como manifestação, Real privilegiou a permanência, a não mudança: “(...) E o aspecto mais extraordinário desse cortejo régio tem sido a sua grande estabilidade no tempo - isto é, durante muito mais de cem anos, o cortejo do maracatu-nação tem permanecido inteiramente estável, virtualmente sem modificação.” Para qualquer maracatuzeiro, ou mesmo estudioso atento, os maracatus dos anos 1980 mudaram em muito quando comparados com os existentes nos dias atuais, seja no toque, fantasias ou relações internas.

${ }^{3}$ Discuti essa reinterpretação dos autores que escreveram sobre os afoxés em LIMA (2009).

${ }^{4}$ Sobre o maracatu enquanto termo polissêmico, ver SILVA (2002) e MAIA (1995). Sobre a polissemia da palavra batuque, ver ABREU (1999, p. 287-290) e REIS (2002).

${ }^{5}$ Sobre o momento favorável que vivem os maracatus-nação, ver LIMA (2009). Sobre a Noite dos Tambores Silenciosos, ver GUILLEN (2006).

${ }^{6}$ Sobre a antropologia evolucionista, ver CASTRO (2005) e BOAS (2004 a; 2004 b).

${ }^{7}$ Para esta questão na historiografia brasileira, ver DANTAS (1988), SANSONE (2004) e CAPONE (2004).

${ }^{8}$ Veja-se os diversos números do Jornal Djumbay e do Negritude, ambos circularam nos anos 1990, mesmo que de forma irregular.

${ }^{9}$ JÚNIOR, Lindivaldo. Afoxés de África no Recife. In: Afoxé - encanto e resistência. Folheto distribuído pela Prefeitura da Cidade do Recife. Encontra-se depositado na Casa do Carnaval.

\section{Referências bibliográficas}

ABREU, Martha. O império do divino - festas religiosas e cultura popular no Rio de Janeiro, 1830-1900. Rio de Janeiro: Nova Fronteira, 1999. 
ALMEIDA, Renato. História da música brasileira. Rio de Janeiro: F. Briguiet \$ Comp., 1942. Vivência e projeção do folclore. Rio de Janeiro: Livraria Agir, 1971.

ANDRADE, Mário. Danças dramáticas do Brasil. 2otomo. Belo Horizonte / Brasília: Ed. Itatiaia / INL / Fundação Nacional Pró-memória, 1982.

ARAÚJO, Alceu Maynard. Folclore Nacional. Danças, recreação, música. V. II. São Paulo: Melhoramentos, 1967. BARTH, Fredrik. A análise da cultura nas sociedades complexas. In: LASK, Tomke (Org). O guru, o iniciador e outras variações antropológicas. Rio de Janeiro: Contracapa, 2000.

BASTIDE, Roger. Imagens do Nordeste mistico em branco e preto. Rio de Janeiro: O Cruzeiro, 1945.

. O carnaval de Recife. Revista do Brasil, abril de 1944.

. Sociologia do folclore brasileiro. São Paulo: Editora Anhambi, 1959.

BOAS, Franz. A formação da antropologia americana - 1883-1911. Rio de Janeiro: Contraponto/ Ed. UFRJ, 2004 (a).

. Antropologia cultural. Rio de Janeiro: Jorge Zahar, 2004 (b).

CAPONE, Stefania. A busca da África no candomblé. Tradição e poder no Brasil. Rio de Janeiro: Pallas/Contracapa, 2004.

CARNEIRO, Edison. Folguedos tradicionais. Rio de Janeiro: Conquista, 1974.

. Dinâmica do folclore. Rio de Janeiro: Civilização Brasileira, 1985.

CASCUDO, Câmara. Vaqueiros e cantadores. Rio de Janeiro: Ediouro, 2000.

CASTRO, Celso. Evolucionismo cultural. Textos de Morgan, Tylor e Frazer. Rio de Janeiro: Jorge Zahar, 2005.

DANTAS, Beatriz Góis. Vovó nagô, papai branco. Usos e abusos da África no Brasil. Rio de Janeiro: Graal, 1988.

GUERREIRO, Goli. A trama dos tambores - a música afro-pop de Salvador. São Paulo: Editora 34, 2000.

GUILLEN, Isabel Cristina Martins. "Noite dos Tambores Silenciosos: ritual e tradição entre os maracatus-nação do Recife". Anais Eletrônicos da 25a. Reuniäo Brasileira de Antropologia. Saberes e Práticas Antropológicas. Desafios para o século XXI. Goiânia, ABA, UFG e Universidade Católica de Goiás, 2006.

HALL, Stuart. Identidade cultural e diáspora. Revista do Patrimônio Histórico e Artístico Nacional, no 24, p. 6875, 1996.

LIMA, Ivaldo Marciano de França. Identidade negra no Recife: maracatus e afoxés. Recife: Bagaço, 2009. . Maracatus e maracatuzeiros: desconstruindo certezas, batendo afayas e fazendo histórias. Recife, 1930-1945.

Recife: Bagaço, 2008. . Maracatus-nação: ressignificando velhas histórias. Recife: Bagaço, 2005.

LODY, Raul Giovanni. Cadernos de folclore - afoxé. Rio de Janeiro, Funarte, 1976.

MAIA, Clarissa Nunes. Sambas, batuques, vozerias e farsas públicas: o controle social sobre os escravos em Pernambuco no século XIX (1850-1888). São Paulo: Annablume, 2008.

PEIXE, Guerra. Maracatus do Recife. Recife: Prefeitura da Cidade do Recife/ Irmãos Vitale, 1980, $2^{a}$ edição.

PRITCHARD, Evans Edward E. Algumas reminiscências e reflexōes sobre o trabalho de campo. In: Bruxaria, oráculos e magia entre os azande. Rio de Janeiro: Jorge Zahar, 2004.

QUERINO, Manuel. Costumes africanos no Brasil. Recife: Fundaj/ Ed. Massangana, 1988.

RAMOS, Arthur. O folk-lore negro do Brasil - demopsychologia e psycanálise. Rio de Janeiro: Civilização Brasileira, 1935.

O negro brasileiro. Recife: Fundaj / Massangana, 1988.

REAL, Katarina. O folclore no carnaval do Recife. Recife: Fundação Joaquim Nabuco/Ed. Massangana, 1990, $2^{a}$ edição.

REIS, João José. Tambores e temores: a festa negra na Bahia na primeira metade do século XIX. In: CUNHA, Maria Clementina Pereira (Org.). Carnavais e outras f(r)estas - Ensaios de história social da cultura. Campinas: Ed. Unicamp / Cecult, 2002, p. 101-151.

RISÉRIO, Antonio. Carnaval ijexá; notas sobre afoxés e blocos do novo carnaval afrobaiano. Salvador: Corrupio, 1981. 
ROCHA, Everardo P. Guimarães. O que é mito. São Paulo: Brasiliense, 1985.

RODRIGUES, Nina. Os africanos no Brasil. Brasília: Ed. UNB, 2004. [1932].

SANSONE. Lívio. Negritude sem etnicidade. Salvador/ Rio de Janeiro: Edufba/ Pallas, 2004.

SILVA, Leonardo Dantas. A corte dos reis do congo e os maracatus do Recife. Notícia bibliográfica e histórica. Campinas: PUC, no 184, p. 43-64, 2002.

SILVA, Maria Auxiliadora Gonçalves. Arqueologia da memória: resgate da mãe África. Tese de doutorado em antropologia, Recife: UFPE, 2007.

VIEIRA FILHO, Raphael Rodrigues. Folguedos negros no carnaval de Salvador (1880-1930). In: SANSONE, Lívio \& SANTOS, Jocélio Teles dos (Orgs). Ritmos em trânsito: sócio-antropologia da música baiana. São Paulo/ Salvador: Dynamis Editorial/ Programa A cor da Bahia/ Programa S.A.M.B.A, 1997.

\section{RESUMO}

Este trabalho objetiva discutir as relaçôes existentes entre os afoxés e as religiōes de divindades e de entidades, especialmente o candomblé, nas cidades do Recife e Olinda entre os anos de 1980 a 2000. Tomados como candomblé de rua por boa parte dos intelectuais do movimento negro em Pernambuco, os afoxezeiros utilizam-se desse discurso para defenderem-se dos ataques feitos por folcloristas, memorialistas e parte significativa dos intelectuais pernambucanos. Estes acusam o afoxé de ser uma manifestação cultural baiana e, por conseguinte, não merecedora de recursos e atençōes dos poderes públicos locais. Mas o que são os afoxés? Quem os faz? Onde moram? A quem serve os discursos de origem das manifestaçôes culturais? Para este trabalho foram utilizados como fonte entrevistas realizadas com afoxezeiros e militantes do movimento negro pernambucano, que serão analisados à luz das novas abordagens teórico-metodológicas da História Social da Cultura, além de noticias dos jornais Diário de Pernambuco e Jornal do Commercio.

Palavras-chave: afoxés, cultura negra, religióes de divindades e de entidades.

\section{ABSTRACT}

This work intent to argue the relations between afoxés and the religions of divinities and entities, especially candomblé, in the cities of Recife and Olinda between the years of 1980 the 2000. Taken as candomble of street for most of the intellectuals of the black movement in Pernambuco, the afoxezeiros are used of this speech to be defended of the attacks made for folklorist, memorialists and part of the intellectuals in Pernambuco. They accuse afoxé to be a Bahia's cultural manifestation and, therefore, not deserving of resources and attentions of them to be able public places. But what they are afoxés? Who makes them? Where those people lives? To who it serves the speeches of origin of the cultural manifestations? For this work they had been used as source interviews carried through with militant afoxezeiros and the black movement of Pernambuco, that will be analyzed to the light of the new approaches of the Social History of the Culture, beyond notice of periodicals Diário de Pernambuco and Jornal do Commercio.

Keywords: afoxés, black culture, religions of divinities and entities. 